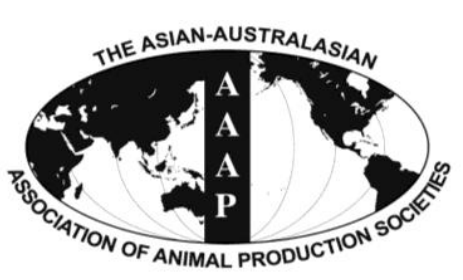

Open Access

Asian Australas. J. Anim. Sci.

Vol. 27 , No. $7:$ : 1013-1018 July 2014

http://dx.doi.org/10.5713/ajas.2013.13579

www.ajas.info

pISSN 1011-2367 elSSN 1976-5517

\title{
Kinetic Behavior of Escherichia coli on Various Cheeses under Constant and Dynamic Temperature
}

\author{
K. Kim, H. Lee, E. Gwak, and Y. Yoon* \\ Department of Food and Nutrition, Sookmyung Women's University, Seoul 140-742, Korea
}

\begin{abstract}
In this study, we developed kinetic models to predict the growth of pathogenic Escherichia coli on cheeses during storage at constant and changing temperatures. A five-strain mixture of pathogenic E. coli was inoculated onto natural cheeses (Brie and Camembert) and processed cheeses (sliced Mozzarella and sliced Cheddar) at 3 to $4 \log$ CFU/g. The inoculated cheeses were stored at 4 , $10,15,25$, and $30^{\circ} \mathrm{C}$ for 1 to $320 \mathrm{~h}$, with a different storage time being used for each temperature. Total bacteria and $E$. coli cells were enumerated on tryptic soy agar and MacConkey sorbitol agar, respectively. E. coli growth data were fitted to the Baranyi model to calculate the maximum specific growth rate $\left(\mu_{\max } ; \log \mathrm{CFU} / \mathrm{g} / \mathrm{h}\right)$, lag phase duration (LPD; h), lower asymptote (log CFU/g), and upper asymptote $(\log \mathrm{CFU} / \mathrm{g})$. The kinetic parameters were then analyzed as a function of storage temperature, using the square root model, polynomial equation, and linear equation. A dynamic model was also developed for varying temperature. The model performance was evaluated against observed data, and the root mean square error (RMSE) was calculated. At $4^{\circ} \mathrm{C}, E$. coli cell growth was not observed on any cheese. However, E. coli growth was observed at $10^{\circ} \mathrm{C}$ to $30^{\circ} \mathrm{C}$ with a $\mu_{\max }$ of 0.01 to $1.03 \log \mathrm{CFU} / \mathrm{g} / \mathrm{h}$, depending on the cheese. The $\mu_{\max }$ values increased as temperature increased, while LPD values decreased, and $\mu_{\max }$ and LPD values were different among the four types of cheese. The developed models showed adequate performance (RMSE $=0.176-0.337$ ), indicating that these models should be useful for describing the growth kinetics of E. coli on various cheeses. (Key Words: Escherichia coli, Cheese, Predictive Model, Dynamic Model)
\end{abstract}

\section{INTRODUCTION}

Cheese is one of the most popular foods globally. The International Dairy Foods Association (IDFA) reported in 2010 , that cheese is the major manufactured dairy product, and that its importance for the dairy industry has grown remarkably. The consumption of cheese has been increasing gradually since the 1990s (Kim et al., 2007). However, some cheese is occasionally contaminated with food-borne pathogens such as Listeria monocytogenes, Staphylococcus aureus, and Escherichia coli (E. coli, Thayer et al., 1998; Kaan Tekinşen and Özdemir, 2006; Jo et al., 2007).

E. coli, a facultative anaerobic gram-negative bacillus, is commonly found in the intestinal flora of man and animals, and certain strains are pathogenic (Olsvik et al.,

\footnotetext{
* Corresponding Author: Yohan Yoon. Tel: +82-2-2077-7585, Fax: +82-2-710-9479, E-mail: yyoon@ sookmyung.ac.kr Submitted Sept. 16, 2013; Revised Jan. 14, 2014; Accepted Feb. 28, 2014
}

1991). Pathogenic E. coli strains are classified by infection and pathologic mechanism: enteropathogenic $E$. coli (EPEC), enteroinvasive E. coli, enterotoxigenic E. coli (ETEC), enterohemorrhagic E. coli (EHEC), and enteroaggregative E. coli (EAEC) (Nataro and Kaper, 1998). Recently, there have been reports from many countries, regarding the isolation of $E$. coli from various cheeses (Haran et al., 2012; Zinke et al., 2012). Moreover, several outbreaks of $E$. coli infections, related to cheese, have been reported (FSN, 2010). Therefore, several countries have a quantitative standard or "zero tolerance" policy for controlling pathogens in cheese (Health Canada, 2008; FDA, 2009).

Predictive models can be used to determine how intrinsic or extrinsic factors affect or interact with growth parameters (Lihono et al., 2003). Moreover, they can predict the growth or survival of bacteria in accordance with a diverse range of parameters, such as storage temperature and storage time (McMeekin et al., 1997). 
Storage temperature is a major factor for bacterial growth, and it can be changed continuously under various circumstances such as transportation, display at retail, and storage at home. Therefore, it is important to describe the growth kinetics of pathogens under dynamic storage conditions.

Although the growth of $E$. coli has been evaluated in raw milk and unpasteurized cheese using predictive models (Sutherland et al., 1995), the growth of pathogenic E. coli on cheese has not been studied, especially in response to varying temperature. Therefore, the objective of this study was to develop a mathematical model that describes the growth kinetics of pathogenic E. coli under constant and dynamic temperature conditions.

\section{MATERIALS AND METHODS}

\section{Inoculum preparation}

Five strains of $E$. coli, NCCP14037 (ETEC), NCCP 14038 (EPEC), NCCP 14039 (EAEC), NCCP 15661 (EPEC), and ATCC11142 (ETEC) were supplied from National Culture Collection for Pathogens. They were cultured in $10 \mathrm{~mL}$ of tryptic soy broth (TSB; Bacto, Becton Dickinson, MD, USA), and incubated at $35^{\circ} \mathrm{C}$ for $2 \mathrm{~h}$. We inoculated $0.1 \mathrm{~mL}$ of each culture suspension into $10 \mathrm{~mL}$ of TSB for subculturing at $35^{\circ} \mathrm{C}$ for $24 \mathrm{~h}$. After incubation, the subcultures were then mixed and harvested by centrifugation for $15 \mathrm{~min}$ at $1,912 \mathrm{~g}$ and $4{ }^{\circ} \mathrm{C}$. The cell pellets were thoroughly washed twice with phosphatebuffered saline (PBS, pH 7.4; $0.2 \mathrm{~g} / \mathrm{L} \mathrm{KH}_{2} \mathrm{PO}_{4}, 1.5 \mathrm{~g} / \mathrm{L}$ $\mathrm{Na}_{2} \mathrm{HPO}_{4}, 8.0 \mathrm{~g} / \mathrm{L} \mathrm{NaCl}, 0.2 \mathrm{~g} / \mathrm{L} \mathrm{KCl}$ in distilled water), followed by serial dilution with PBS to obtain approximately 5 to $6 \log \mathrm{CFU} / \mathrm{mL}$.

\section{Sample preparation and inoculation}

Two commercial natural cheeses (Brie and Camembert; no antimicrobial included) and two processed cheeses (sliced Mozzarella and sliced Cheddar; no antimicrobial included) were purchased at a retail store. The natural cheeses were cut into $15 \mathrm{~g}$ portions, and transferred into sample bags. The surfaces of the cheeses were inoculated with $0.1 \mathrm{~mL}$ of inoculum at 3 to $4 \log \mathrm{CFU} / \mathrm{g}$. The cheese samples were then massaged to spread the bacteria, and sealed (Food Guard VP5700, Rollpack, Gyeonggi, Korea). In addition, $0.1 \mathrm{~mL}$ portions of inoculum were inoculated onto each slice (18 g) of processed cheese (Mozzarella and Cheddar), using a sterile bent spreader. The processed cheese samples were then covered aboriginally. Two samples were then placed in a plastic bag, and sealed, followed by storage at $4^{\circ} \mathrm{C}(1,320 \mathrm{~h}), 10^{\circ} \mathrm{C}(768 \mathrm{~h}), 15^{\circ} \mathrm{C}$ $(120 \mathrm{~h}), 25^{\circ} \mathrm{C}(48 \mathrm{~h})$, and $30^{\circ} \mathrm{C}(24 \mathrm{~h})$.

\section{Experimental growth analysis}

Cheese samples were analyzed 9 to 16 times during storage, depending on the storage temperature. Thirty milliliter of $0.1 \%$ buffered peptone water (BPW; Difco, Becton Dickinson, MD, USA) was added to the natural cheese samples and the mixture was homogenized for 120 min in a blender (BagMixer; Interscience, France), while processed cheese samples were transferred into a filter bag (Sample bag, 3M, Korea), containing $30 \mathrm{~mL}$ of BPW, and blended for $2 \mathrm{~min}$. The homogenates were then serially diluted with BPW. Aliquots $(0.1 \mathrm{~mL})$ of the diluents were surface-plated on tryptic soy agar (TSA; Difco) and MacConkey sorbitol agar (Mac; Difco) for determining total bacterial and E. coli counts, respectively. The plates were incubated at $35^{\circ} \mathrm{C}$ for $24 \mathrm{~h}$, and the colonies were manually counted. The $\mathrm{pH}$ values of the homogenates were measured via a digital $\mathrm{pH}$ meter (Accumet, Denver Instruments, CO, NY, USA), and the water activity, $a_{w}$, of the samples was determined by a water activity meter (Aquaspector, NAGY Messsysteme, Gäufelden, Germany).

\section{Primary model}

The E. coli growth data was fitted to the Baranyi model (Baranyi and Robert, 1994), using DMFit (Institute of Food Research, Norwich, UK) to estimate the maximum specific growth rate $\left(\mu_{\max } ; \log \mathrm{CFU} / \mathrm{g} / \mathrm{h}\right)$, the lag phase duration (LPD; h), the lower asymptote $\left(N_{0} ; \log \mathrm{CFU} / \mathrm{g}\right)$, and the upper asymptote $\left(N_{\max } ; \log \mathrm{CFU} / \mathrm{g}\right)$.

\section{Secondary model}

The kinetic parameters from the primary model were further analyzed as a function of storage temperature. The square root model and polynomial model were used for natural cheese and processed cheese, respectively, as follows:

$$
\begin{aligned}
& \sqrt{\mu_{\max }}=a_{\mu} \times\left(T-T_{\min }\right) \\
& \mu_{\max }=a_{1}+a_{2} \times T+a_{3} \times T^{2}
\end{aligned}
$$

where $a_{\mu}$ is the slope of the linear regression for the square root of $\mu_{\max }$ and $T$ is the temperature $\left({ }^{\circ} \mathrm{C}\right) . T_{\min }$ is the theoretical minimum temperature. $a_{i}$ is the coefficient of a polynomial equation. In addition, a linear equation was fitted to the square root of the inverse LPD for both natural and processed cheeses using the expression,

$$
\sqrt{\frac{1}{L P D}}=N_{o}+a_{L P D} \times a_{L P D} \times T
$$

where $a_{\mathrm{LPD}}$ are the slopes of the regression lines for the square root of the inverse LPD, and $T$ is temperature $\left({ }^{\circ} \mathrm{C}\right)$. 


\section{Validation}

To validate the models, $E$. coli cell counts were obtained experimentally. These data were then compared with the predicted $E$. coli cell counts, which were estimated by our models. Subsequently, the root mean square error (RMSE) was calculated to evaluate the model performance as follows:

$$
\mathrm{RMSE}=\sqrt{\frac{\sum{\text { (observed values - } \text { predicted values })^{2}}_{n-1}}{n-1}}
$$

where $\mathrm{n}$ is the number of observations.

\section{Dynamic model}

A study by Lee et al. (2008) reported that the mean temperature and storage time in a retail store were $7^{\circ} \mathrm{C}\left(T_{\min }\right.$, $-2^{\circ} \mathrm{C} ; T_{\max }, 22.9^{\circ} \mathrm{C}$ ) and 2 days, respectively, and that purchased cheeses were then transported in a car at $18^{\circ} \mathrm{C}$ for up to $1 \mathrm{~h}$. In addition, Bahk (2010) showed that the mean temperature and storage time for a home refrigerator were $4^{\circ} \mathrm{C}\left(T_{\min },-5^{\circ} \mathrm{C} ; T_{\max }, 14^{\circ} \mathrm{C}\right)$ and 10 days, respectively. Therefore, E. coli populations were simulated by using the mathematical model defined by Baranyi and Roberts (1994) and a temperature profile based on the above studies $\left(4^{\circ} \mathrm{C}\right.$ to $\left.14^{\circ} \mathrm{C}\right)$.

\section{Statistical analysis}

The experiments were repeated twice with two samples per repeat $(\mathrm{n}=4)$. The growth parameters $\left(\mu_{\max }\right.$ LPD, $N_{0}$, and $N_{\max }$ ) were analyzed using the general llinear model procedure of SAS version 9.2 (SAS Institute, NC, USA).
Mean comparisons were performed by using a pairwise $t$ test with the criterion for significance set at $\mathrm{p}<0.05$.

\section{RESULTS AND DISCUSSION}

$\mathrm{pH}$ values were similar for the four types of cheese and bacterial growth was not affected by $\mathrm{pH}$ (data not shown). $E$. coli growth was not observed for any cheese type at $4^{\circ} \mathrm{C}$ (data not shown). The processed Cheddar cheese showed $E$. coli growth at $15^{\circ} \mathrm{C}$ to $30^{\circ} \mathrm{C}$, and the other cheeses had bacterial growth at $10^{\circ} \mathrm{C}$ to $30^{\circ} \mathrm{C}$. LPD values decreased as the storage temperature increased $(\mathrm{p}<0.05)$, but no significant difference was observed between the cheeses (Table 1). $\mu_{\max }$ values increased $(\mathrm{p}<0.05)$ when storage temperature increased, and the $\mu_{\max }$ values of natural cheeses were higher $(\mathrm{p}<0.05)$ than those of the processed cheeses (Table 1). The $a_{w}$ values of Brie, Camembert, Mozzarella slice, and Cheddar slice cheese were 0.991, $0.987,0.975$, and 0.973 , respectively. hus, these lower $\mu_{\max }$ values of processed cheeses may have been caused by a lower $a_{w}(0.973$ to 0.975$)$, compared with those (0.987 to 0.991 ) of the natural cheeses. E. coli growth slows as $a_{w}$ approaches its minimum (0.950) (Aberoumand, 2010). The low $a_{w}$ of processed cheeses may be caused by evaporation during the heating process; $\mathrm{NaCl}$ concentrations were similar among the cheeses. In addition, the $N_{\max }$ values were lower $(\mathrm{p}<0.05)$ in processed cheese than in natural cheese (Table 1 ). The $R^{2}$ values of the primary models ranged from 0.918 to 0.998 , indicating that the fit between the primary model and the E. coli growth data was appropriate (Table 1).

To evaluate the effect of storage temperature on kinetic

Table 1. Kinetic parameters (mean \pm standard error) of pathogenic Escherichia coli on natural and processed cheeses, calculated by the Baranyi equation (Baranyi and Roberts, 1994)

\begin{tabular}{|c|c|c|c|c|c|c|c|}
\hline Cheese & & $\begin{array}{c}\text { Storage } \\
\text { temperature }\left({ }^{\circ} \mathrm{C}\right)\end{array}$ & LPD (h) & $\begin{array}{c}\mu_{\max } \\
(\log \mathrm{CFU} / \mathrm{g} / \mathrm{h})\end{array}$ & $\begin{array}{c}N_{0} \\
(\log \mathrm{CFU} / \mathrm{g})\end{array}$ & $\begin{array}{c}N_{\max } \\
(\log \text { CFU/g) }\end{array}$ & $R^{2}$ \\
\hline \multirow{8}{*}{$\begin{array}{l}\text { Natural } \\
\text { cheese }\end{array}$} & \multirow{4}{*}{$\begin{array}{l}\text { Brie } \\
\text { cheese }\end{array}$} & 10 & $20.13 \pm 9.60^{\mathrm{A}}$ & $0.03 \pm 0.00^{\mathrm{E}}$ & $3.6 \pm 0.1^{\mathrm{A}}$ & $8.6 \pm 0.3^{\mathrm{B}}$ & 0.987 \\
\hline & & 15 & $9.61 \pm 2.47^{\mathrm{B}}$ & $0.07 \pm 0.01^{\mathrm{DE}}$ & $3.5 \pm 0.0^{\mathrm{A}}$ & $9.4 \pm 0.2^{\mathrm{A}}$ & 0.992 \\
\hline & & 25 & $5.40 \pm 0.55^{\mathrm{B}}$ & $0.45 \pm 0.03^{\mathrm{B}}$ & $3.6 \pm 0.1^{\mathrm{A}}$ & $9.1 \pm 0.2^{\mathrm{AB}}$ & 0.973 \\
\hline & & 30 & $5.68 \pm 0.46^{\mathrm{B}}$ & $0.94 \pm 0.10^{\mathrm{A}}$ & $3.6 \pm 0.0^{\mathrm{A}}$ & $9.1 \pm 0.1^{\mathrm{AB}}$ & 0.996 \\
\hline & \multirow{4}{*}{$\begin{array}{l}\text { Camembert } \\
\text { cheese }\end{array}$} & 10 & $24.49 \pm 3.85^{\mathrm{AB}}$ & $0.03 \pm 0.00^{\mathrm{E}}$ & $3.4 \pm 0.1^{\mathrm{A}}$ & $8.4 \pm 0.3^{\mathrm{B}}$ & 0.998 \\
\hline & & 15 & $10.35 \pm 2.08^{\mathrm{B}}$ & $0.09 \pm 0.01^{\mathrm{DE}}$ & $3.4 \pm 0.0^{\mathrm{A}}$ & $9.3 \pm 0.1^{\mathrm{A}}$ & 0.984 \\
\hline & & 25 & $5.74 \pm 1.06^{\mathrm{B}}$ & $0.44 \pm 0.03^{\mathrm{B}}$ & $3.4 \pm 0.0^{\mathrm{A}}$ & $9.1 \pm 0.1^{\mathrm{AB}}$ & 0.982 \\
\hline & & 30 & $5.92 \pm 0.71^{\mathrm{B}}$ & $1.03 \pm 0.07^{\mathrm{A}}$ & $3.6 \pm 0.0^{\mathrm{A}}$ & $9.0 \pm 0.1^{\mathrm{AB}}$ & 0.985 \\
\hline \multirow{7}{*}{$\begin{array}{l}\text { Processed } \\
\text { cheese }\end{array}$} & \multirow{4}{*}{$\begin{array}{l}\text { Mozzarella } \\
\text { slice cheese }\end{array}$} & 10 & $3.44 \pm 8.10^{\mathrm{A}}$ & $0.01 \pm 0.00^{\mathrm{E}}$ & $3.0 \pm 0.1^{\mathrm{B}}$ & $6.3 \pm 0.1^{\mathrm{CD}}$ & 0.918 \\
\hline & & 15 & $9.22 \pm 4.45^{\mathrm{B}}$ & $0.06 \pm 0.01^{\mathrm{DE}}$ & $3.1 \pm 0.0^{\mathrm{B}}$ & $7.7 \pm 0.1^{\mathrm{CD}}$ & 0.984 \\
\hline & & 25 & $4.30 \pm 1.88^{\mathrm{B}}$ & $0.25 \pm 0.05^{\mathrm{CD}}$ & $3.3 \pm 0.1^{\mathrm{B}}$ & $7.8 \pm 0.2^{\mathrm{D}}$ & 0.988 \\
\hline & & 30 & $1.79 \pm 0.69^{\mathrm{B}}$ & $0.33 \pm 0.01^{\mathrm{C}}$ & $3.0 \pm 0.0^{\mathrm{B}}$ & $8.0 \pm 0.1^{\mathrm{E}}$ & 0.992 \\
\hline & \multirow{3}{*}{$\begin{array}{l}\text { Cheddar slice } \\
\text { cheese }\end{array}$} & 15 & $35.95 \pm 16.22^{\mathrm{A}}$ & $0.03 \pm 0.00^{\mathrm{E}}$ & $2.8 \pm 0.0^{\mathrm{B}}$ & $7.2 \pm 0.6^{\mathrm{CD}}$ & 0.967 \\
\hline & & 25 & $6.83 \pm 1.15^{\mathrm{B}}$ & $0.18 \pm 0.01^{\mathrm{D}}$ & $2.9 \pm 0.2^{\mathrm{A}}$ & $7.3 \pm 0.0^{\mathrm{C}}$ & 0.977 \\
\hline & & 30 & $6.08 \pm 2.04^{\mathrm{B}}$ & $0.28 \pm 0.07^{\mathrm{CD}}$ & $3.0 \pm 0.1^{\mathrm{B}}$ & $7.0 \pm 0.1^{\mathrm{CD}}$ & 0.988 \\
\hline
\end{tabular}

LPD, lag phase duration; $\mu_{\max }$, maximum specific growth rate; $N_{0}$, lower asymptote, $N_{\max }$, upper asymptote.

${ }^{\mathrm{A}-\mathrm{E}}$ Different letters in a same column mean significantly different at $\mathrm{p}<0.05$. 
parameters such as $\mu_{\max }$ and LPD, secondary models were developed (Figures 1 and 2). When there was no growth of E. coli, e.g., at $4^{\circ} \mathrm{C}, \mu_{\max }$ was estimated to be zero, and the length of the storage period was estimated to be the LPD, which is the period of the time, showing no growth. The model predictions were close to the experimentally observed kinetic data, with high $R^{2}$ values ( 0.890 to 0.994 ), indicating that the secondary models were valid for describing the effect of storage temperature on kinetic parameters.

To validate our model, predicted $\mu_{\max }$ and LPD values were calculated via the secondary model at specific temperatures $\left(18^{\circ} \mathrm{C}, 23^{\circ} \mathrm{C}\right.$, and $\left.28^{\circ} \mathrm{C}\right)$. These predicted kinetic parameters were then used to predict $E$. coli cell counts at given storage times in accordance with the primary model. The predicted $E$. coli cell counts were then compared with the observed $E$. coli cell counts, which were obtained from our experiments. The RMSE values of Brie, Camembert, Mozzarella, and Cheddar slice cheeses, indicating the distance between observed values and predicted values, were $0.264,0.218,0.176$, and 0.337 , respectively. , depending on the cheese. This result indicates that the model performance is adequate. The RMSE values

(A) Brie

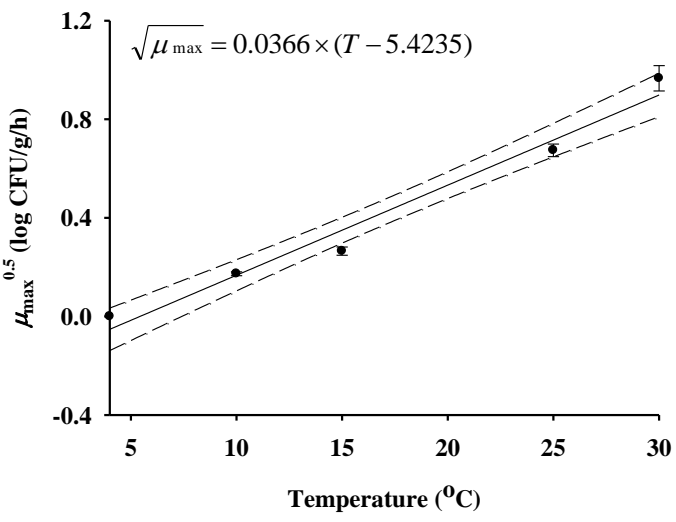

(C) Brie

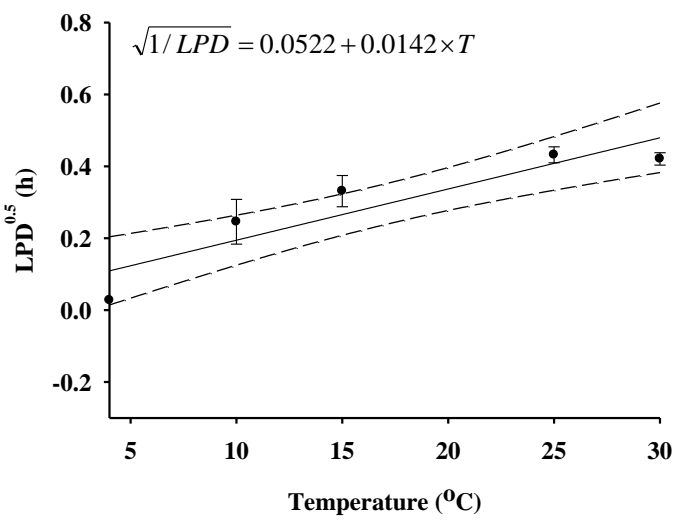

for models by Pérez-Rodríguez et al. (2013) and Skřivanová et al. (2008) were 0.30 to 1.33 and 0.29 to 0.78 , respectively, and this was considered adequate by the authors. Lee et al. (2012) concluded that their model was adequate with RMSE values of 0.326 to 0.361 . Therefore, the performance of the model described by this study can be considered adequate.

E. coli growth on cheese was also simulated for changing storage temperatures. $h_{0}$ values, which indicate the initial physiological state of bacteria (Grijspeerdt and Vanrolleghem, 1999) were calculated to be 1.816 to 2.074 for natural cheese and 0.549 to 0.874 for processed cheese (Figure 3). Although some experimental data were not very close to the predicted values, most data were within $95 \%$ confidence intervals. This result suggests that the dynamic models are useful for prediction of $E$. coli cell growth on natural and processed cheeses under dynamic temperature conditions.

In conclusion, the models developed in this study can be used to describe $E$. coli growth kinetics on natural cheeses (Brie and Camembert) and processed cheeses (sliced Mozzarella and sliced Cheddar). Such models could prove useful for exposure analysis in microbial risk assessment.

\section{(B) Camembert}

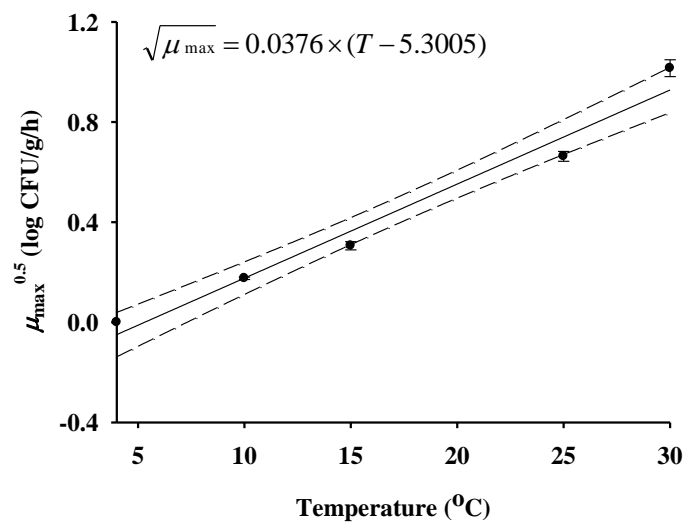

(D) Camembert

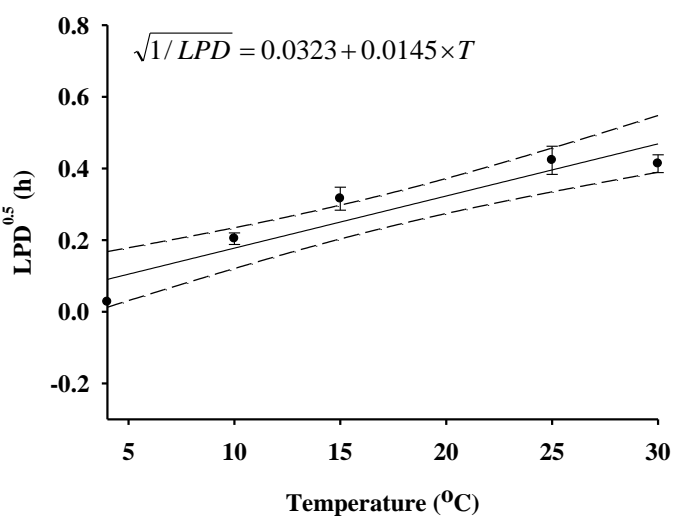

Figure 1. Square root model for $\mu_{\max }$ (A-B) and linear equation for lag phase duration (C-D) developed for Brie and Camembert cheeses. $\bullet$, observed value; - , predicted line; ---, 95\% confidence interval. 
(A) Mozzarella slice

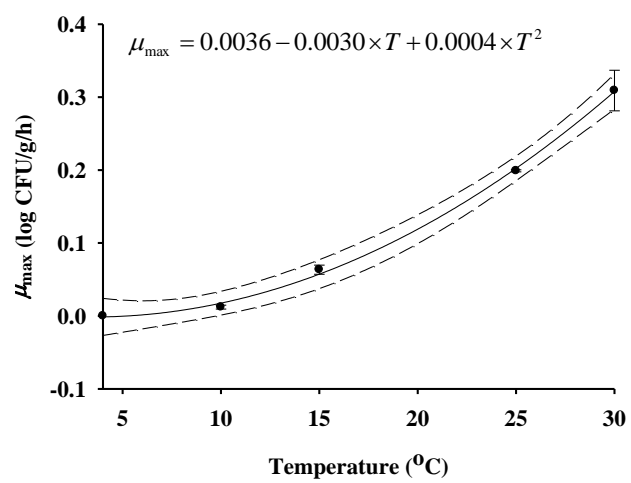

(C) Mozzarella slice

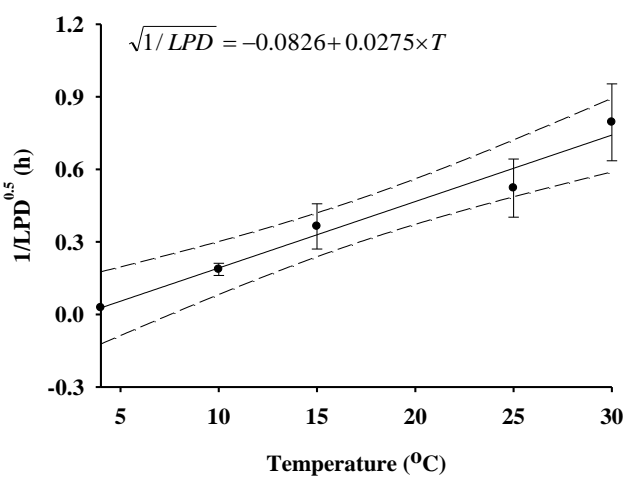

(B) Cheddar slice

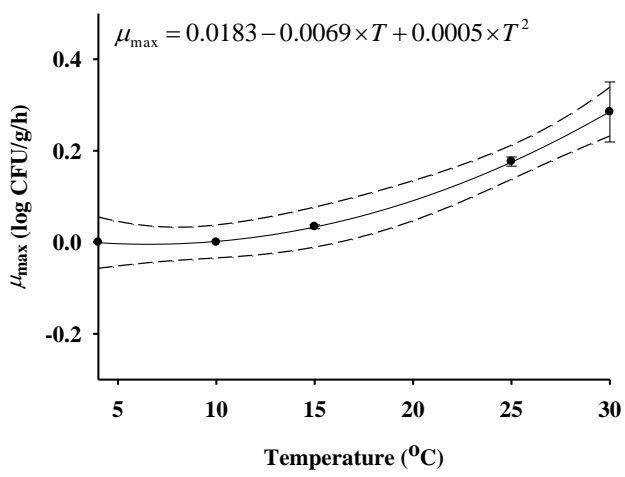

(D) Cheddar slice

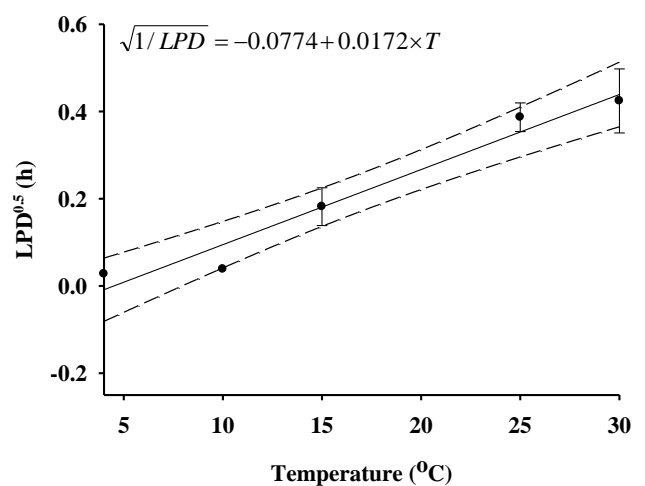

Figure 2. Polynomial equation for $\mu_{\max }$ (A-B) and linear equation for lag phase duration (C-D) developed for Mozzarella slice and Cheddar slice cheeses. $\bullet$, observed value; - , predicted line; ---, 95\% confidence interval.

(A) Brie

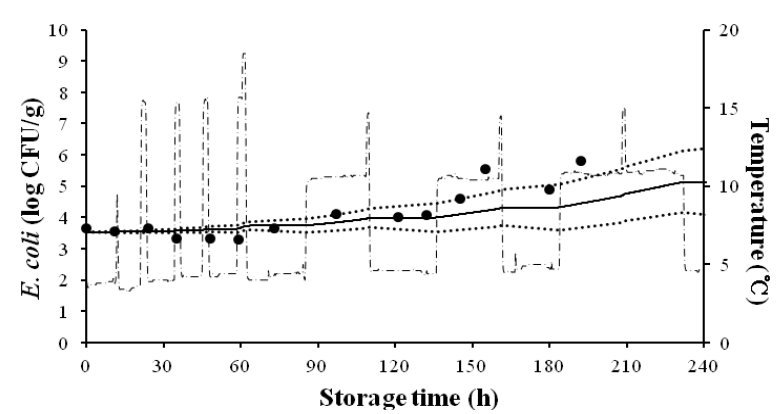

(C) Mozzarella slice

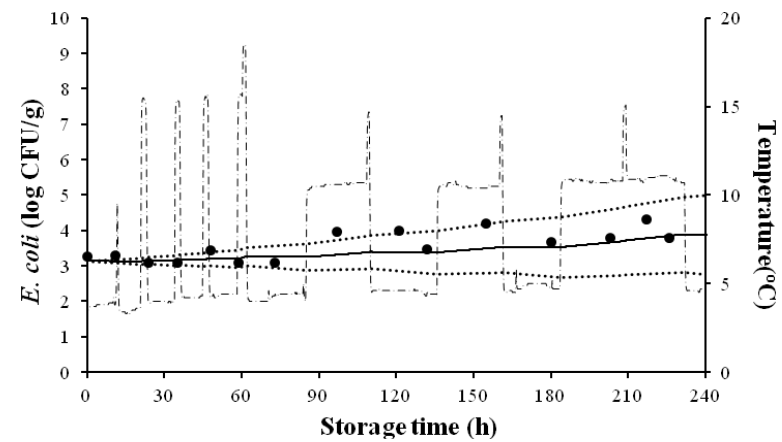

(B) Camembert

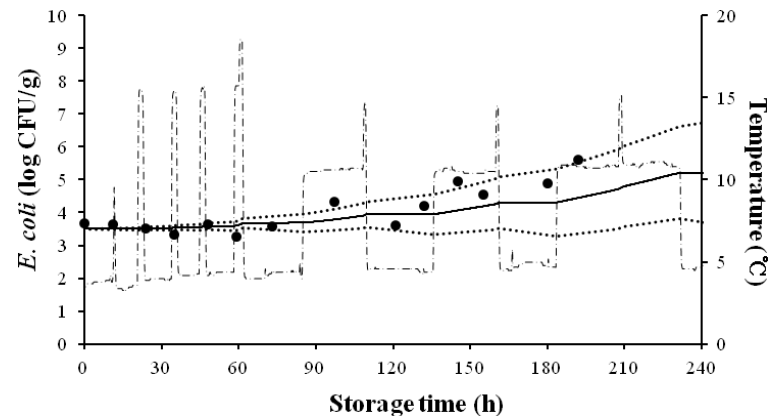

(D) Cheddar slice

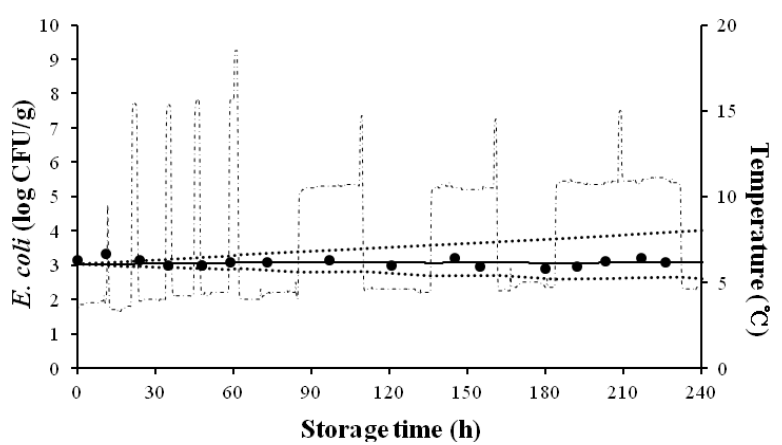

Figure 3. Predicted Escherichia coli growth on Brie cheese (A), Camembert cheese (B), Mozzarella slice cheese (C), and Cheddar slice cheese (D) under dynamic temperature condition. $\bullet$, observed data, - , predicted line, $\cdots \cdots, 95 \%$ confidence interval, $-\cdot-$, temperature. 


\section{ACKNOWLEDGMENTS}

This research was supported by a grant (13162MFDS927) from Ministry of Food and Drug Safety in 2013.

\section{REFERENCES}

Aberoumand, A. 2010. Estimation of microbiological variations in minced lean fish products. World J. Fish Mar. Sci. 2:204-207.

Bahk, G. J. 2010. Statistical probability analysis of storage temperatures of domestic refrigerator as a risk factor of foodborne illness outbreak. Korean J. Food Sci. Technol. 42:373-376.

Baranyi, J. and T. A. Roberts. 1994. A dynamic approach to predicting bacterial growth in food. Int. J. Food Microbiol. 23:277-294.

FDA. 2009. Guidance for FDA staff, compliance policy guide. http://www.fda.gov/downloads/ICECI/ComplianceManuals/Co mpliancePolicyGuidanceManual/UCM192468.pdf. Accessed October 28, 2013.

FSN (Food Safety News). 2010. Costco-linked E. coli cheese outbreak sickens 25. http://www.foodsafetynews.com/2010/1 1/costco-cheese-infects-25-in-five-states-with-e-coli-o157h7/\#. U1aDPk2KDIU. Accessed April 22, 2014.

Grijspeerdt, K. and P. Vanrolleghem. 1999. Estimating the parameters of the Baranyi model for bacterial growth. Food Microbiol. 16:593-605.

Haran, K. P., S. M. Gooden, D. Boxrud, S. Jawahir, J. B. Bender, and S. Sreevatsan. 2012. Prevalence and characterization of Staphylococcus aureus, including methicillin-resistant Staphylococcus aureus, isolated from bulk tank milk from Minnesota dairy farms. J. Clin. Microbiol. 50:688-695.

Health Canada. 2008. Health Products and Food Branch (HPFB) Standards and Guidelines for Microbiological Safety of Food. http://www.hc-sc.gc.ca/fn-an/res-rech/analy-meth/micro bio/volume1/intsum-somexp-eng.php. Accessed September 10, 2013.

IDFA (International Dairy Foods Association). 2010. Dairy facts, 2010 ed. International Dairy Foods Association, Washington, DC, USA. p. 66-76.

Jo, C., H. J. Kim, D. H. Kim, W. K. Lee, J. S. Ham, and M. W. Byun. 2007. Radiation sensitivity of selected pathogens in ice cream. Food Control 18:859-865.

Kaan Tekinşen, K. and Z. Özdemir. 2006. Prevalence of foodborne pathogens in Turkish Van otlu (Herb) cheese. Food Control 17:707-711.
Kim, H. J., B. S. Song, J. H. Kim, J. Choi, J. W. Lee, C. Jo, and M. W. Byun. 2007. Application of gamma irradiation for the microbiological safety of sliced cheddar cheese. J. Radiat. Ind. 1:15-19.

Lee, J-Y., H-J. Suk, H. Lee, S. Lee, and Y. Yoon. 2012. Application of probabilistic model to calculate probabilities of Escherichia coli O157:H7 growth on polyethylene cutting board. Korean J. Food Sci. Anim. 32:62-67.

Lee, Y. S., J. H. Ha, K. H. Park, S. Y. Lee, Y. J. Choi, D. H. Lee, S. H. Park, E. S Moon, K. Ryu, H. S. Shin, and S. D. Ha. 2008. Survey on storage temperature of domestic major chilled foods in refrigerator. J. Fd Hyg. Safety 23:304-308.

Lihono, M. A., A. F. Mendonca, J. S, Dickson, and P. M. Dixon. 2003. A predictive model to determine the effects of temperature, sodium pyrophosphate, and sodium chloride on thermal inactivation of starved Listeria monocytogenes in pork slurry. J. Food Prot. 66:1216-1221.

McMeekin, T. A., J. Brown, K. Krist, D. Miles, K. Neumeyer, D. S. Nichols, J. Olley, K. Presser, D. A. Ratkowsky, T. Ross, M. Slater, and S. Soontranon. 1997. Quantitative microbiology: a basis for food safety. Emerg. Infect. Dis. 3:541-550.

Nataro, J. P. and J. B. Kaper. 1998. Diarrheagenic Escherichia coli. Clin. Microbiol. Rev. 11:142-201.

Olsvik, Ø., Y. Wasteson, A. Lund, and E. Hornes. 1991. Pathogenic Escherichia coli found in food. Int. J. Food Microbiol. 12:103-113.

Perez-Rodriguez, F., G. D. Posada-Izquierdo, A. Valero, R.M. García-Gimeno, and G. Zurera. 2013. Modelling survival kinetics of Staphylococcus aureus and Escherichia coli 0157:H7 on stainless steel surfaces soiled with different substrates under static conditions of temperature and relative humidity. Food Microbiol. 33:197-204.

Skřivanová, E., Z. Molatová, and M. Marounek. 2008. Effects of caprylic acid and triacylglycerols of both caprylic and capric acid in rabbits experimentally infected with enteropathogenic Escherichia coli O103. Vet. Microbiol. 126:372-376.

Sutherland, J. P., A. J. Bayliss, and D. S. Braxton. 1995. Predictive modeling of growth of Escherichia coli O157:H7: the effects of temperature, $\mathrm{pH}$ and sodium chloride. Int. J. Food Microbiol. 25:29-49.

Thayer, D. W., G. Boyd, A. Kim, J. B. Fox Jr, and H. M. Farrell Jr. 1998. Fate of gamma-irradiated Listeria monocytogenes during refrigerated storage on raw or cooked turkey breast meat. J. Food Prot. 61:979-987.

Zinke, C., M. Winter, E. Mohr, and V. Kromker. 2012. Occurrence of methicillin-resistant Staphylococcus aureus in cheese produced in German farm-dairies. Adv. Microbiol. 2:629-633. 